\title{
Plasma Cytomegalovirus (CMV) DNA Load Predicts CMV Disease and Survival in AIDS Patients
}

\author{
Stephen A. Spector, ${ }^{\star}$ Rodney Wong, ${ }^{\ddagger}$ Karen Hsia, ${ }^{*}$ Marshall Pilcher, ${ }^{\star}$ and Mary Jean Stempien ${ }^{\ddagger}$ \\ $*$ University of California at San Diego, La Jolla, California 92093; and ${ }^{\ddagger}$ Roche Global Development, Palo Alto, California 94304
}

\begin{abstract}
In this study, baseline plasma from 619 persons with acquired immunodeficiency syndrome (AIDS) (median CD4 ${ }^{+}$ lymphocyte count $-21 / \mu \mathrm{l}$ ) who participated in a trial to determine the efficacy of oral ganciclovir for cytomegalovirus (CMV) disease prevention were evaluated for CMV DNA load by qualitative and quantitative polymerase chain reaction (PCR), and correlated with the development of CMV disease and survival. For participants without detectable plasma CMV DNA, the 12-mo Kaplan-Meier CMV disease event rate was $14 \%$ and $1 \%$ for the placebo and ganciclovir groups, respectively $(P<0.001)$. For $P C R$ positive participants, CMV disease developed in $43 \%$ of placebo and $26 \%$ ganciclovir recipients $(P<0.017)$. Among placebo recipients, CMV PCR positivity was associated with a 3.4-fold increased risk of developing CMV disease $(P<0.001)$ whereas $\mathrm{CD}^{+}{ }^{+}$lymphocyte count was not a useful predictor $(P=0.47)$. A positive plasma CMV DNA PCR was also associated with a 2.5 -fold increased risk of death. Each $\log _{10}$ increase in baseline CMV DNA load was associated with a 3.1-fold increase in CMV disease $(P<0.001)$ and a 2.2 -fold increase in mortality $(P<0.001)$. These data indicate that the risk of developing CMV disease and death in persons with advanced AIDS is directly related to the quantity of CMV DNA in plasma, and is a better predictor than CD4 ${ }^{+}$ lymphocyte count in this population. (J. Clin. Invest. 1998. 101:497-502.) Key words: CMV in AIDS - markers for prevention of CMV disease in AIDS - quantitative CMV PCR • CMV load and survival in AIDS • CMV retinitis
\end{abstract}

\section{Introduction}

Human cytomegalovirus $(\mathrm{CMV})^{1}$ diseases, including retinitis, colitis, and encephalitis, occur in $25-40 \%$ of persons with AIDS $(1,2)$ and have been associated with decreased survival after diagnosis (3-5). Considerable advances have been made in the treatment of AIDS patients with CMV disease and currently three drugs, ganciclovir, foscarnet, and cidofovir, have

Address correspondence to Dr. Stephen A. Spector, University of California, San Diego, Clinical Sciences Building, 9500 Gilman Drive, La Jolla, CA 92093-0672. Phone: 619-534-7170; FAX: 619-534-7411; E-mail: saspector@ucsd.edu

Received for publication 2 July 1997 and accepted in revised form 20 November 1997.

1. Abbreviation used in this paper: $\mathrm{CMV}$, cytomegalovirus.

J. Clin. Invest.

(C) The American Society for Clinical Investigation, Inc. 0021-9738/98/01/0497/06 \$2.00

Volume 101, Number 2, January 1998, 497-502

http://www.jci.org demonstrated efficacy for the treatment of CMV retinitis (6-8). Despite progress in the treatment of CMV retinitis and other CMV syndromes, disease recurrences with progression are common (9). Thus, considerable efforts have focused on developing approaches to prevent CMV disease in persons with AIDS $(10,11)$.

A number of clinical and laboratory markers have been used to identify HIV-1-infected persons at risk for development of CMV disease. The $\mathrm{CD}^{+}{ }^{+}$lymphocyte count, and assays that detect acute CMV infection and quantitate virus load, have helped to identify persons at highest risk for CMV disease (12-16). However, little information exists on the ability of virologic markers to distinguish AIDS patients that are most likely to benefit from intervention strategies designed to prevent CMV disease. Additionally, no data are available on the association of CMV DNA load and survival in a large cohort of persons with AIDS.

A recent study evaluating the efficacy of oral ganciclovir in the prevention of CMV disease in persons with advanced HIV-1 infection demonstrated that study participants receiving ganciclovir had a risk reduction of $49 \%$ for development of CMV disease compared with those randomized to placebo (Kaplan-Meier estimates at 12 mo: 26\% incidence of CMV disease for placebo group versus $14 \%$ CMV disease for ganciclovir group; 95\% confidence interval, $0.36-0.73 ; P<0.001)(10)$. At $12 \mathrm{mo}$, the Kaplan-Meier estimate of the rate of death was $26 \%$ in the placebo group and $21 \%$ in the ganciclovir group (relative risk, 0.81; 95\% confidence interval, 0.61-1.07; $P=$ 0.14). During the conduct of this CMV prevention study, participants had plasma specimens obtained at baseline before instituting study medication. We have now investigated the value of plasma CMV DNA PCR in predicting the development of disease during the succeeding 12 mo and overall survival for the study cohort.

\section{Methods}

Study design. The original study consisted of 725 participants randomized in a 2:1 ratio to receive ganciclovir or placebo, respectively. The $619(85 \%)$ patients evaluated in this viral load study comprised all persons for whom baseline plasma samples were available (201 placebo recipients and 418 ganciclovir recipients). The median CD4 ${ }^{+}$ lymphocyte count for the cohort was 21 cells per microliter, $99 \%$ were males and the median age was $38 \mathrm{yr}$. No study participants had a history of CMV disease and none had received CMV antiviral therapy. Participants had no evidence of CMV retinitis on dilated eye examination by an experienced ophthalmologist before entry into the study. Participants were evaluated every 2 mo for signs consistent with clinical CMV disease and were examined by an experienced ophthalmologist for the presence of CMV retinitis. Full criteria for study entry and establishing the presence of CMV disease have been described in detail previously (10). The study was conducted before the availability of antiretrovirals with activity against the HIV protease.

Quantitation of CMV DNA in plasma. Plasma samples for CMV DNA quantitation were collected at each of 19 participating study 
A

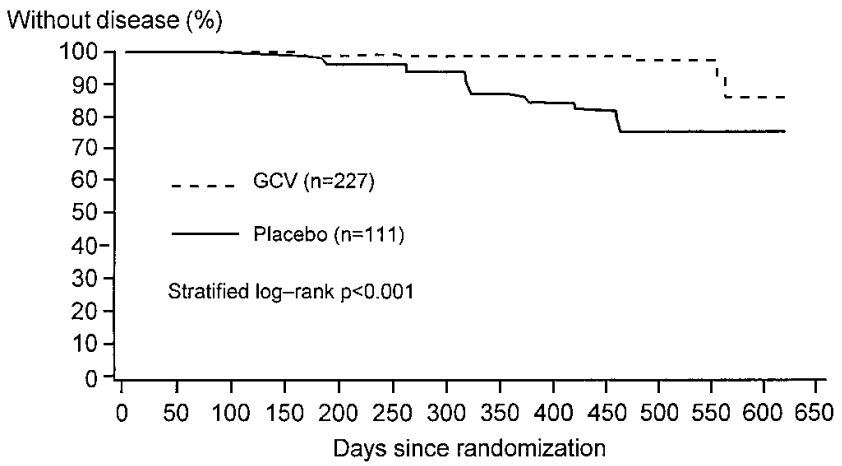

B

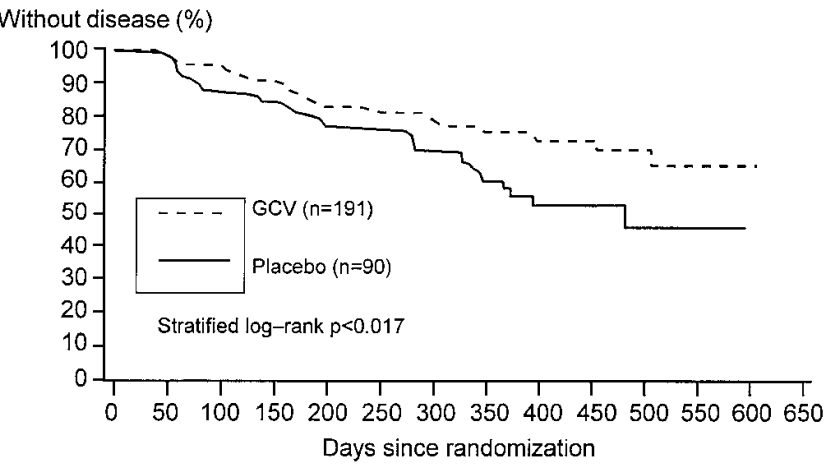

Figure 1. Kaplan-Meier event rates from baseline to development of CMV disease for study participants $(A)$ PCR negative and $(B)$ PCR positive.

sites and frozen at $-20^{\circ} \mathrm{C}$ to $-80^{\circ} \mathrm{C}$ until shipped on dry ice to the central repository. Specimens were then stored at $-80^{\circ} \mathrm{C}$ until processed. CMV DNA was measured from $10 \mu \mathrm{l}$ of plasma using a CMV DNA PCR procedure $(14,15)$. Specimens were first evaluated by qualitative assay as to the presence of CMV DNA in plasma using methods previously described except CMV DNA was extracted using a silica extraction method (17). Briefly, $100 \mu \mathrm{l}$ of each plasma was treated with $900 \mu \mathrm{l}$ lysis buffer and $40 \mu \mathrm{l}$ silica suspension for $10 \mathrm{~min}$ at room temperature in a $2 \mathrm{ml}$ microtube. The lysis buffer contained $4.23 \mathrm{M}$ guanidinium thiocyanate, $20 \mathrm{mM}$ disodium-EDTA, and $1.0 \%$ Triton $\mathrm{X}-100$ in $0.1 \mathrm{M}$ Tris- $\mathrm{HCl}$ ( $\mathrm{pH}$ 6.4). The nucleic acid-silica complex was spun down for $15 \mathrm{~s}$ at $12,000 \mathrm{~g}$ in a microcentrifuge. The pellet was washed twice with wash buffer containing $4.23 \mathrm{M}$ guanidinium thiocyanate in $0.1 \mathrm{M}$ Tris- $\mathrm{HCl}(\mathrm{pH} 6.4)$, followed by two washes with $70 \%$ ethanol and a wash with acetone. The pellet was dried at $56^{\circ} \mathrm{C}$ for $10 \mathrm{~min}$ in a heat block, resuspended with $200 \mu \mathrm{l}$ sterile Millipore water, and incubated for $10 \mathrm{~min}$ at $56^{\circ} \mathrm{C}$. The nucleic acid supernatant was recovered after centrifugation for $2 \mathrm{~min}$ at $12,000 \mathrm{~g}$ in a microcentrifuge. This supernatant was then clarified by one or more centrifugations to be completely void of silica particles and stored at $-20^{\circ} \mathrm{C}$ until used in PCR $(14,15)$. The sensitivity of the qualitative PCR assay was 500 copies per ml. Those identified as DNA positive were quantitated for CMV DNA using a competitive plasma DNA PCR (QC-PCR) technique $(15,18)$. The assay could quantitate the presence of $\geq 25$ copies per $10 \mu \mathrm{l}$ ( $\geq 2,500$ copies per milliliter) CMV DNA in plasma. Plasma specimens positive for CMV DNA were categorized as either positive but below 2,500 copies per milliliter or quantitated when above 2,500 copies per milliliter.

Table I. 12-mo Kaplan-Meier Event Rates of CMV Disease for Study Participants Plasma CMV DNA PCR Negative at Baseline

\begin{tabular}{lcccc}
\hline & Ganciclovir & Placebo & $P$ value & $\begin{array}{c}\text { Relative risk } \\
95 \% \text { CI }\end{array}$ \\
\hline $\begin{array}{l}\text { No. of subjects } \\
\text { CMV event rate }\end{array}$ & 227 & 111 & & 0.16 \\
$\leq 50$ CD 4 cells per $\mu \mathrm{l}$ & $1 \%$ & $14 \%$ & $<0.0001$ & $(0.06,0.40)$ \\
$\quad \begin{array}{l}\text { No. of subjects } \\
\text { CMV event rate }\end{array}$ & 193 & 95 & & 0.21 \\
$>50$ CD 4 cells per $\mu l$ & $2 \%$ & $13 \%$ & $<0.001$ & $(0.08,0.56)$ \\
$\begin{array}{l}\text { No. of subjects } \\
\text { CMV event rate }\end{array}$ & 34 & 16 & & \\
& $0 \%$ & $23 \%$ & 0.002 & 0 \\
\hline
\end{tabular}

The QC-PCR assay used for these studies in preliminary comparisons has been found to correlate well with other qualitative CMV assays. In a study presented by Erice et al., our QC-PCR assay had a correlation of 0.997 with a PCR assay under development by Roche Molecular Systems (Alameda, CA), 0.75 with a branch chain DNA assay being developed by Chiron Corporation (Emeryville, CA) and 0.75 with a CMV antigenemia assay (INCSTAR Corporation, Stillwater, MN) (19).

Statistical analysis. Kaplan-Meier estimates for event rates at 12 mo were computed (20). The relative risk of CMV disease (or death) and $95 \%$ confidence intervals for relative risk were computed from a Cox model with treatment (placebo or ganciclovir) as the single covariate (21). Spearman correlation coefficients were used to measure the association between CMV load and $\mathrm{CD}^{+}$counts among all patients with both measurements at baseline. The comparison of baseline $\mathrm{CD}^{+}{ }^{+}$count and PCR for predicting CMV disease (or death) used relative risks from a Cox model with a quantitative covariate for baseline $\mathrm{CD}^{+}{ }^{+}$count and a binary covariate for baseline PCR (negative, positive) among placebo patients. The increased relative risk of CMV disease (or death) from increasing quantitative PCR at baseline used a Cox model with $\log _{10}$ (quantitative baseline PCR) as the covariate among placebo patients with a positive baseline PCR.

\section{Results}

Qualitative PCR. At baseline, 90 (45\%) of 201 placebo recipients were positive by qualitative CMV PCR and 191 (46\%) of 418 ganciclovir recipients were positive. For the 338 (111 placebo; 227 ganciclovir) participants who were PCR negative at baseline, the 12-mo Kaplan-Meier CMV disease event rate was $14 \%$ in the placebo group compared with $1 \%$ in the ganciclovir-treated group (relative risk, 0.16 ; $95 \%$ confidence interval, 0.06-0.40) (Fig. $1 A$ ). The benefit of ganciclovir was observed both for study participants with above or below 50 $\mathrm{CD}^{+}$lymphocytes per microliter at baseline (Table I).

Although a benefit of ganciclovir was also observed for patients PCR positive at baseline, there was an increase in the number of persons developing CMV endpoints in both treated and placebo groups. The 12-mo CMV event rate for participants receiving placebo was $43 \%$ compared with $26 \%$ for the ganciclovir group (relative risk, $0.58,95 \%$ confidence interval, 0.37-0.91; $P=0.017$ ) (Fig. $1 B$ ). Benefit was observed for participants with above or below $50 \mathrm{CD}^{+}$lymphocytes per microliter at baseline (Table II).

CMV PCR positivity was a better predictor of the risk of 
Table II. 12-mo Kaplan-Meier Event Rates of CMV Disease for Study Participants Plasma CMV DNA PCR Positive at Baseline

\begin{tabular}{lcccc}
\hline & Ganciclovir & Placebo & $P$ value & $\begin{array}{c}\text { Relative risk } \\
95 \% \text { CI }\end{array}$ \\
\hline $\begin{array}{l}\text { No. of subjects } \\
\text { CMV event rate }\end{array}$ & 191 & 90 & & 0.58 \\
$\leq 50$ CD 4 cells per $\mu \mathrm{l}$ & $26 \%$ & $43 \%$ & 0.017 & $(0.37,0.91)$ \\
$\begin{array}{l}\text { No. of subjects } \\
\text { CMV event rate }\end{array}$ & 176 & 84 & & 0.60 \\
$>$ 50 CD 4 cells per $\mu \mathrm{l}$ & $28 \%$ & $43 \%$ & 0.028 & $(0.38,0.95)$ \\
$\begin{array}{l}\text { No. of subjects } \\
\text { CMV event rate }\end{array}$ & 15 & 16 & & 0.34 \\
& $7 \%$ & $33 \%$ & 0.27 & $(0.05,2.5)$ \\
\hline
\end{tabular}

developing CMV disease than was $\mathrm{CD}^{+}$lymphocyte count in this group of patients with advanced AIDS. As assessed using a Cox regression model including both variables applied to patients who received placebo, baseline CMV PCR positivity was associated with a 3.4-fold increase in the risk of developing CMV disease $(P<0.0001)$. CD4 ${ }^{+}$lymphocyte count did not have a statistically significant association with CMV disease risk $(P=0.47)$.

Quantification of CMV plasma load. The 281 plasma specimens positive for CMV DNA at baseline were quantitated using a competitive PCR assay. For the 90 PCR positive placebo recipients, the median copies per milliliter was 3,600 (range: $<2,500-150,000$ copies per milliliter). For the 191 ganciclovir recipients, the median copies per milliliter was 3,900 (range: $<2,500-2,300,000$ copies per milliliter) (Fig. 2). The development of CMV disease significantly correlated with the quantity of CMV DNA present in plasma at baseline. Among patients who were CMV PCR positive at baseline and received placebo, each $\log _{10}$ increase in baseline viral load was associated with a 3.1-fold increase in the risk of developing CMV disease $(P<0.0001)$ (Fig. 3).

The relationship of baseline CMV load and baseline $\mathrm{CD}^{+}$ lymphocyte count was also examined. CMV loads of $10^{5}$ copies per milliliter or higher occurred almost entirely among patients with CD4+ lymphocyte counts of $<50$ cells per microliter (Fig. 4). CMV load showed a statistically significant but weak rank correlation with CD4+ count (Spearman $r=-0.2$, $P<0.0001)$.

Plasma CMV DNA and survival. Study participants randomized to placebo who were CMV plasma PCR negative at baseline had an overall mortality at 12 mo of $16.1 \%$ compared with $37.7 \%$ for those PCR positive (Fig. $5, A$ and $B$ ). Similarly, ganciclovir recipients who were CMV plasma PCR negative at baseline had a 12 -mo mortality rate of $11.4 \%$ compared with $32.5 \%$ for those who were PCR positive (Fig. 5, $A$ and $B$ ). Although there was a trend toward improved survival with ganciclovir whether CMV DNA PCR negative or positive at baseline, in neither group was overall survival found to be significantly improved.

CMV PCR positivity also correlated strongly with survival in a Cox regression analysis. Among patients receiving placebo, the relative risk of death associated with a positive PCR at baseline was $2.5(P=0.0006) . \mathrm{CD}^{+}$lymphocyte counts had no statistically significant association with risk of death within this population of patients with already low $\mathrm{CD} 4^{+}$lymphocyte counts $(P=0.28)$.

Quantified CMV load also correlated with survival over and above the correlation noted for CMV positivity. Among patients who were CMV PCR positive at baseline and received

\section{Percentage of Subjects}

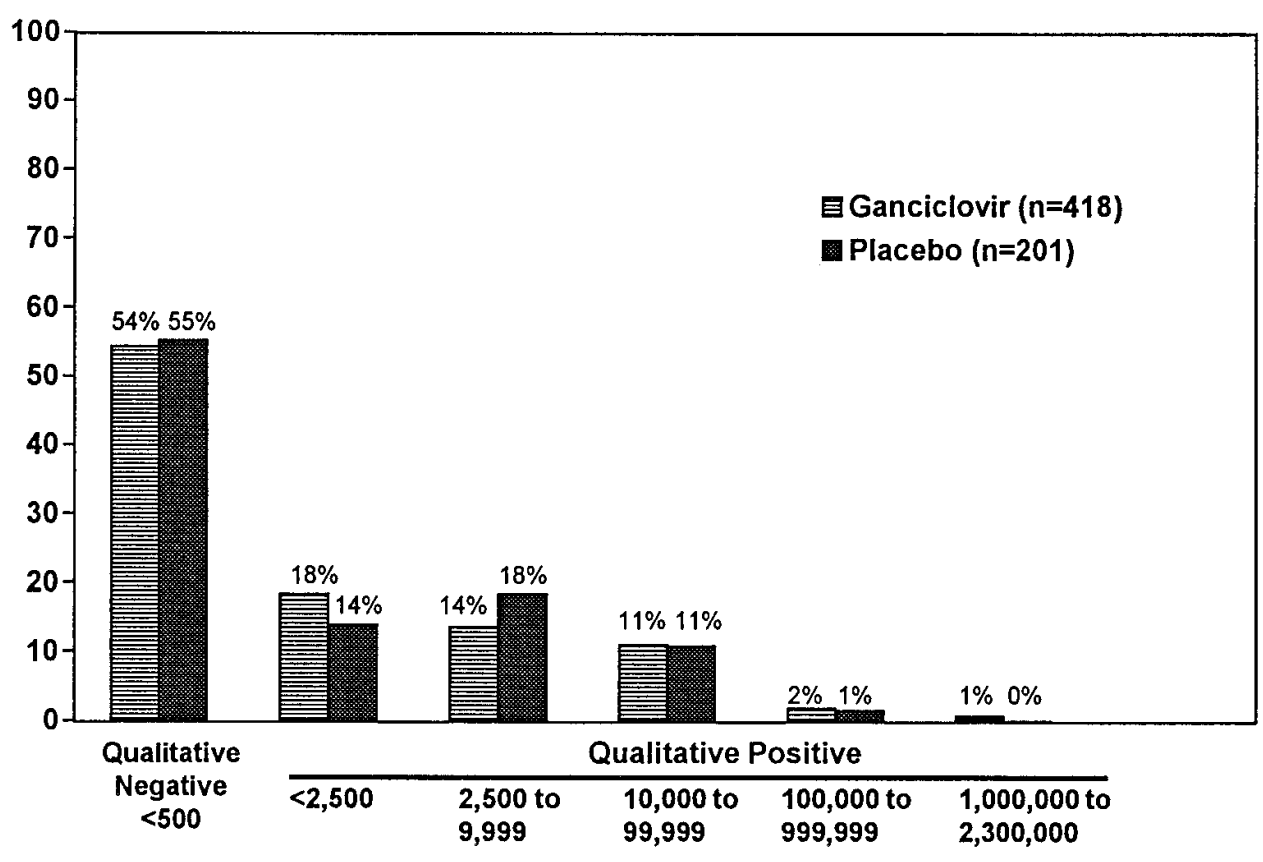

Baseline CMV DNA (copies/ml)
Figure 2. Frequency of distribution of CMV DNA in baseline plasma samples for participants randomized to receive oral ganciclovir or placebo. 
A

Proportion Free of Disease

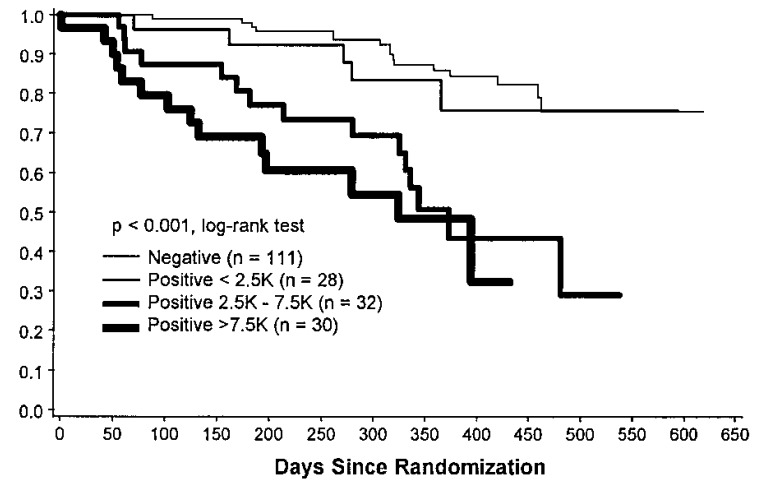

B

Proportion Free of Disease

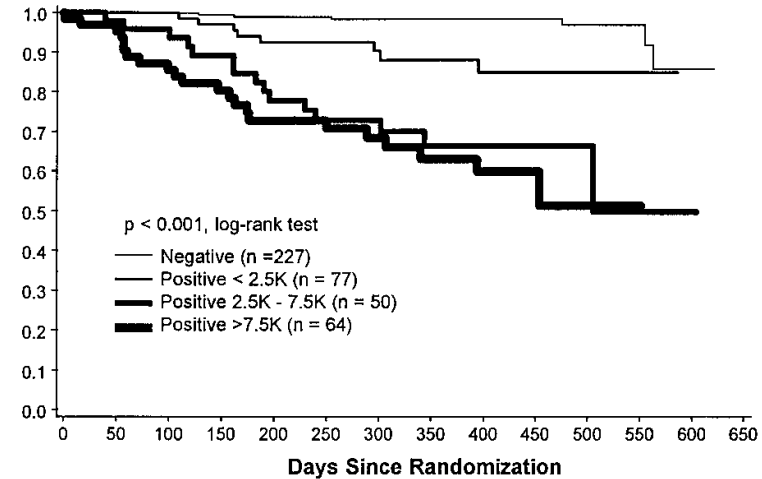

Figure 3. Kaplan-Meier curves from baseline to development of CMV disease for study participants based on CMV DNA PCR status and quantity of DNA in plasma for subjects randomized to $(A)$ placebo and $(B)$ ganciclovir. CMV DNA loads presented divide PCR positive group randomized to receive placebo into three approximately equal size groups.

placebo, each $\log _{10}$ increase in baseline viral load was associated with a 2.2-fold increase in the risk of death $(P<0.0001)$ (Fig. $5 A$ ).

\section{Discussion}

CMV is currently the most common and serious opportunistic pathogen to which persons with advanced AIDS are suscepti- ble, and for which, until recently, there was no effective means of prevention. The recent study of oral ganciclovir has demonstrated that CMV diseases can be prevented in some persons with AIDS (10). However, the ability to quantify relative risk for CMV disease would help target preventive strategies to those persons most likely to receive benefit. The results of this study are strikingly similar to recent findings in HIV-1-infected individuals that single determinations of the quantity of HIV-1

\section{Baseline CMV DNA (Copies/ml)}

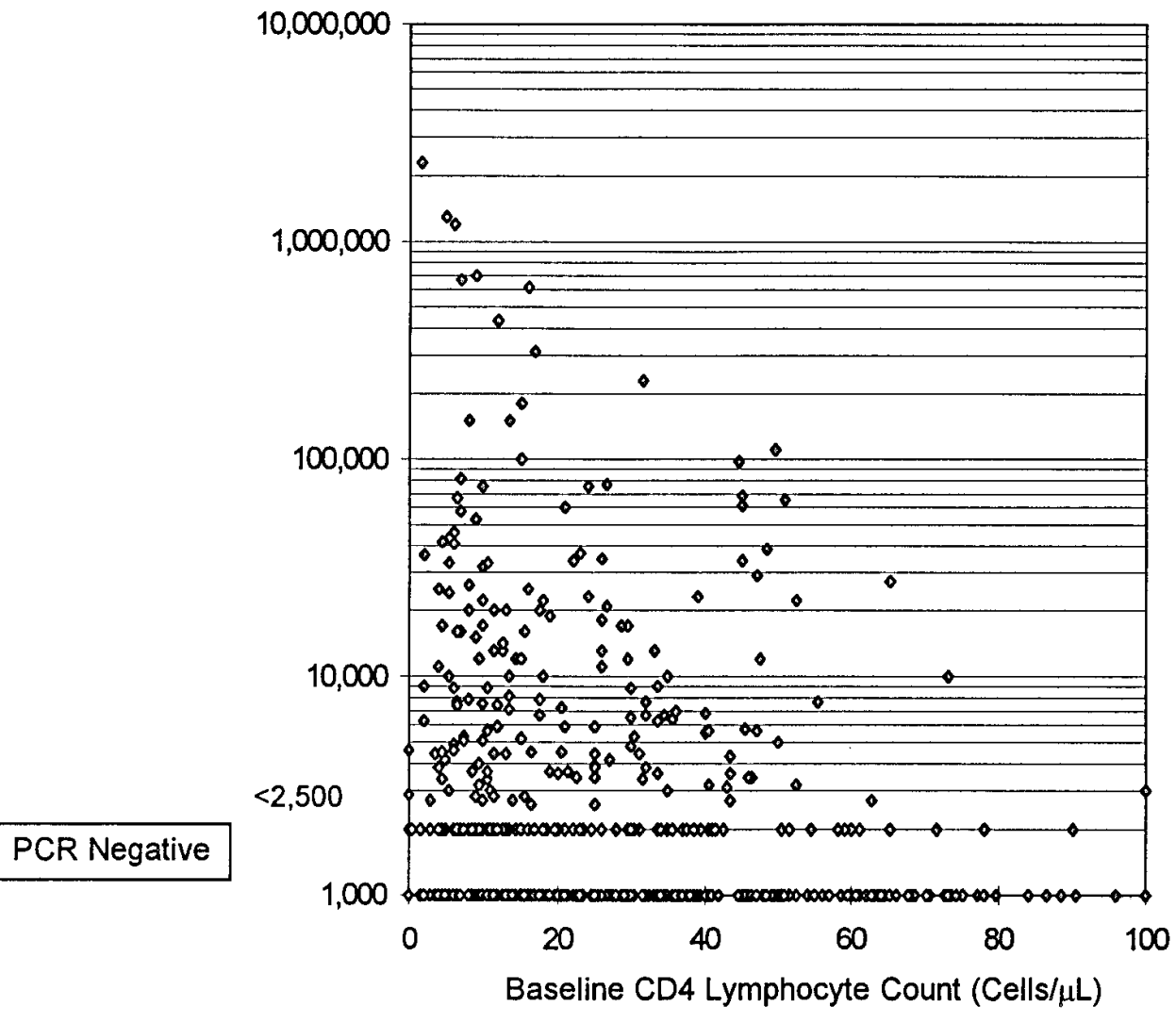

Figure 4. Relation between baseline $\mathrm{CD} 4^{+}$lymphocyte counts and plasma CMV DNA concentration ( $\log _{10}$ scale). Spearman $r=-0.2$, $P<0.0001$. 
A

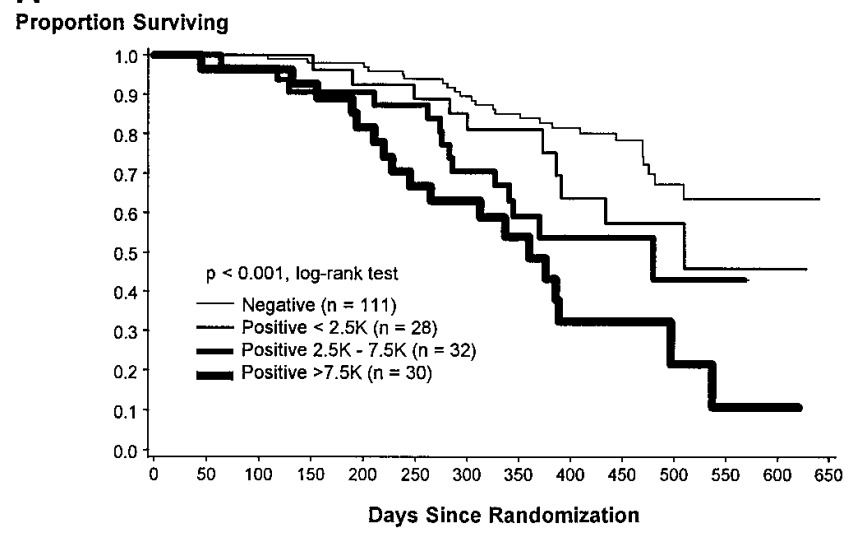

B

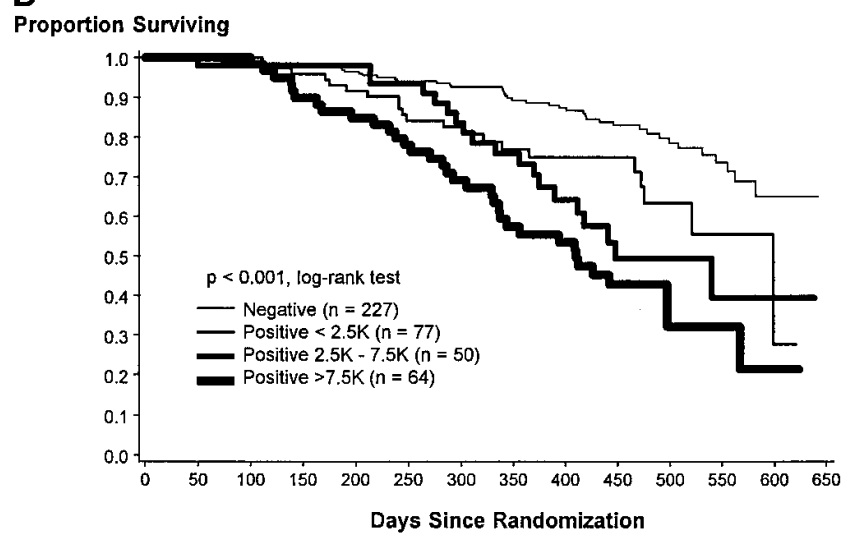

Figure 5. Kaplan-Meier curves from baseline to death for study participants based on CMV DNA PCR status and quantity of DNA in plasma for subjects randomized to $(A)$ placebo and $(B)$ ganciclovir.

RNA in plasma are predictive of the rate of disease progression in subsequent years (22). However, in our study, subjects had already developed advanced HIV-1 disease and were at high risk for development of opportunistic infections and death.

Considerable previous data have indicated that the $\mathrm{CD}^{+}$ lymphocyte count is a strong predictor of risk for CMV disease in AIDS patients $(1,2)$. The data from this study demonstrate that among HIV-infected persons with low $\mathrm{CD} 4^{+}$lymphocyte counts $(\leq 100 / \mu l)$, the presence of CMV DNA in plasma identifies those at highest risk for development of CMV disease. The presence or absence of CMV DNA in plasma clearly differentiates persons at risk for CMV disease and defines two distinct groups for whom CMV disease prevention can be targeted. The first group consists of those AIDS patients who have not reactivated CMV in their blood as determined by CMV plasma PCR. For this group, oral ganciclovir is highly effective in preventing the development of CMV disease. Those PCR negative patients who received oral ganciclovir at 12 mo had only a $1 \%$ incidence of CMV disease compared with $14 \%$ for the placebo group. Thus for true prophylaxis, oral ganciclovir demonstrated excellent efficacy for prevention of CMV disease. In contrast, study participants who were CMV plasma PCR positive at baseline constituted a significantly higher risk group. Despite ganciclovir's effectiveness in this population (a $42 \%$ reduction in risk of CMV disease), those receiving oral ganciclovir still had a $26 \%$ incidence of CMV disease at 12 mo. Thus, the efficacy of oral ganciclovir for CMV disease prevention in patients with active CMV infection, or as preemptive treatment, is considerably less than when used as true prophylaxis. However, it should be noted that the duration of time that participants entering the study had been CMV PCR positive is unknown, and that oral ganciclovir preemptive treatment initiated after the first indication of PCR positivity might demonstrate greater efficacy.

The data from this study further demonstrate that the quantity of CMV DNA present in plasma provides useful additional information. As CMV load increases, there is a concomitant increase in the risk of AIDS patients developing CMV disease. Based on previous studies in persons with AIDS $(13,15,23,24)$ as well as after organ transplantation $(25,26)$, it is possible that subjects with high CMV loads had already seeded their retinas with CMV before initiating ganciclovir treatment, and that in this setting oral ganciclovir was ineffective as preemptive therapy.

The data presented here further demonstrate an increased risk of death as CMV load increases and provide evidence for an important role of CMV as a potential cofactor in late-stage HIV-1 infection. Of interest, the increase in mortality with high CMV DNA load was independent of CD4 $4^{+}$lymphocyte count, although the median $\mathrm{CD}^{+}$count was $\sim 20 / \mu$ for each group evaluated. Whether the reactivation of CMV and the presence of high levels of CMV DNA reflect an inability of the host to control all viral infections including HIV-1 as well as CMV is unknown. Studies are in progress to examine if high levels of CMV DNA in plasma are associated with similarly high levels of HIV-1 RNA.

In the CMV disease prevention study, a survival trend was observed (relative risk, $0.81,95 \%$ confidence interval, $0.63-1.07, P=0.14$ ) in favor of ganciclovir for the entire cohort and for each CMV plasma load. These results suggest that an antiviral with anti-CMV activity greater than that achieved with oral ganciclovir might decrease CMV load to a point where significant improvement in survival as well as CMV disease could be achieved. In this regard, several drugs with activity against CMV with good oral bioavailability including an oral prodrug of ganciclovir are in clinical trials and may also prove useful for CMV disease prevention and improved survival (27-29).

This study also demonstrates an important distinction in approaches for the prevention of CMV disease. Strategies designed for prophylaxis should be directed at persons without evidence of active CMV infection defined in this study as plasma negative for CMV DNA as detected by PCR. This approach is likely to be highly successful although considerations of drug toxicities, convenience, and cost will determine the extent to which treatments for true prophylaxis are used in persons with AIDS. An additional consideration is that the $14 \%$ rate of CMV disease in this population after 12 mo may be considered too low to recommend universal prophylaxis. A second approach to the prevention of CMV disease would be to use ganciclovir for preemptive treatment of persons identified to have CMV DNA present in their plasma. The $45 \%$ rate of CMV disease at 12 mo in the PCR positive group would 
seem to warrant this approach. This preventive strategy may require an initial course of intravenous ganciclovir followed by oral therapy. Clinical trials will be necessary to confirm the benefit of this regimen.

In summary, these data indicate that the presence and quantity of CMV DNA in plasma is an excellent marker for the risk of development of CMV disease and survival. Important criteria for demonstrating the adequacy of a marker for CMV disease and survival have been met: $(a)$ the presence or absence of CMV DNA present at baseline is highly predictive of the subsequent development of CMV disease and mortality; (b) there is a strong correlation between the quantity of CMV DNA present in plasma and the development of CMV disease and survival; and $(c)$ an active anti-CMV agent, ganciclovir, decreases the incidence of CMV disease in persons positive for plasma CMV DNA. Use of CMV DNA in plasma should help guide future studies designed to prevent CMV disease and improve survival in persons with AIDS.

\section{Acknowledgments}

We thank Michael Crager for statistical assistance, and the investigators and patients who participated in the Roche 1654 Study.

This research was supported by a grant from Roche Global Development and by the University of California, San Diego Center for AIDS Research AI-36214.

\section{References}

1. Bloom, J.N., and A.G. Palestine. 1988. The diagnosis of cytomegalovirus retinitis. Ann. Intern. Med. 109:963-969.

2. Drew, W.L. 1992. Cytomegalovirus infection in patients with AIDS. Clin. Infect. Dis. 14:608-615.

3. Webster, A., A.N. Phillips, C.A. Lee, G. Janossy, P.B. Kernoff, and P.D. Griffiths. 1992. Cytomegalovirus (CMV) infection CD4 ${ }^{+}$lymphocyte counts, and the development of AIDS in HIV-1-infected hemophiliac patients. Clin. Exp. Immunol. 88:6-9.

4. Detels, R., C.T. Leach, K. Hennessey, Z. Liu, B.R. Visscher, J.D. Cherry, and J.V. Giorgi. 1994. Persistent cytomegalovirus infection of semen increases risk of AIDS. J. Infect. Dis. 169:766-768.

5. Frenkel, L.D., S. Gaur, M. Tsolia, R. Scudder, R. Howell, and H. Kesarwala. 1990. Cytomegalovirus infection in children with AIDS. Rev. Infect. Dis. 12:S820-S826.

6. Crumpacker, C.S. 1996. Ganciclovir. N. Engl. J. Med. 335:721-729.

7. Palestine, A.G., M.A. Polis, M.D. De Smet, B.F. Baird, J. Falloon, J.A. Kovacs, R.T. Davey, J.J. Zurlo, K.M. Zunich, and M. Davis. 1991. A randomized, controlled trial of foscarnet in the treatment of cytomegalovirus retinitis in patients with AIDS. Ann. Intern. Med. 115:665-673.

8. Lalezari, J.P., R.J. Stagg, B.D. Kupperman, G.N. Holland, F. Kramer, D.V. Ives, M. Youle, M.R. Robinson, W.L. Drew, and H.S. Jaffe. 1997. Intravenous cidofovir for peripheral cytomegalovirus retinitis in patients with AIDS. Ann. Intern. Med. 126:257-263.

9. Studies of Ocular Complications of AIDS Research Group in Collaboration with the AIDS Clinical Trials Group. 1996. Combination of foscarnet and ganciclovir therapy vs. monotherapy for the treatment of relapsed cytomegalovirus retinitis in patients with AIDS. Arch. Ophthalmol. 114:23-32.

10. Spector, S.A., G.F. McKinley, J.P. Lalezari, T. Samo, R. Andruczk, S. Follansbee, P.D. Sparti, D.V. Havlir, G. Simpson, W. Buhles, et al, for the Roche Cooperative Oral Ganciclovir Study Group. 1996. Oral ganciclovir for the prevention of cytomegalovirus disease in persons with AIDS. N. Engl. J. Med. 334:1491-1497.

11. Feinberg, J., D. Cooper, and S. Hurwitz. 1996. Phase III international study of valaciclovir (VACV) for cytomegalovirus (CMV) prophylaxis in patients with advanced HIV disease. Abstracts of the XI International Confer- ence on AIDS. July 7-12. Vancouver, Canada. Creative Direction \& Design Signals, Design Group, Inc. Vancouver, Canada, p. 225. Abstract Th. B300.

12. Gerna, G., F. Baldanti, M. Zavattoni, A. Sarasini, E. Percivalle, and M.G. Revello. 1992. Monitoring of ganciclovir sensitivity of multiple human cytomegalovirus strains coinfecting blood of an AIDS patient by an immediateearly antigen plaque assay. Antivir. Res. 19:333-345.

13. Rasmussen, L., S. Morris, D. Zipeto, J. Fessel, R. Wolitz, A. Dowling, and T.C. Merigan. 1995. Quantitation of human cytomegalovirus DNA from peripheral blood cells of human immunodeficiency virus-infected patients could predict cytomegalovirus retinitis. J. Infect. Dis. 171:177-182.

14. Spector, S.A., R. Merrill, D. Wolf, and W.M. Dankner. 1992. Detection of human cytomegalovirus in plasma of AIDS patients during acute visceral disease by DNA amplification. J. Clin. Microbiol. 30:2359-2365.

15. Shinkai, M., S.A. Bozzette, W. Powderly, P. Frame, and S.A. Spector. 1997. Utility of urine and leukocyte cultures and plasma DNA PCR for identification of AIDS patients at risk for developing human cytomegalovirus disease. J. Infect. Dis. 175:302-308.

16. Bowen, E.F., P. Wilson, A. Cope, C. Sabin, P. Griffiths, C. Davey, M. Johnson, and V. Emery. 1996. Cytomegalovirus retinitis in AIDS patients: influence of cytomegaloviral load on response to ganciclovir, time to recurrence and survival. AIDS (Lond.). 10:1515-1520.

17. Boom, R., C.J.A. Sol, M.M. Salimans, C.L. Jansen, P.M. Wertheim-van Dillen, and J. van der Noordaa. 1990. Rapid and simple method for purification of nucleic acids. J. Clin. Microbiol. 28:495-503.

18. Shinkai, M., and S.A. Spector. 1995. Quantitation of human cytomegalovirus (HCMV) DNA in cerebrospinal fluid by competitive PCR in AIDS patients with different HCMV central nervous system diseases. Scand. J. Infect. Dis. 27:559-561.

19. Erice, A., C. Crumpacker, W. Britt, W.L. Drew, R. Hillam, S. Kao, I. Kolberg, M. Landry, N. Lurain, J. Manischewitz, et al. 1996. Quantitation of cytomegalovirus (CMV) load in blood fractions of patients with AIDS; a complete study of different laboratory methods. Abstracts of the 3rd Conference, Retroviruses and Opportunistic Infections, Session 25. Jan 28-Feb 1. Washington, D.C. Infectious Diseases Society of America for the Foundation for Retrovirology and Human Health, Alexandria, VA, p. 83. Abstract 166.

20. Kaplan, E.L., and P. Meier. 1958. Nonparametric estimation from incomplete observations. J. Am. Stat. Assoc. 53:457-481.

21. Cox, D.R., and D. Oakes. 1984. Analysis of Survival Data, Chapman and Hall, London.

22. Mellors, J.W., C.R. Rinaldo, P. Gupta, R.M. White, J.A. Todd, and L.A. Kingsley. 1996. Prognosis in HIV-1 infection predicted by the quantity of virus in plasma. Science. 272:1167-1170.

23. Bowen, E.F., P.F. Wilson, D.C. Johnson, P.D. Griffiths, and V.C. Emery. 1996. Use of PCR to detect asymptomatic CMV retinitis. Abstracts of the XI International Conference on AIDS. July 7-12. Vancouver, Canada. Creative Direction \& Design Signals, Design Group, Inc. Vancouver, Canada, p. 218. Abstract Th. A. 394.

24. Dodt, K.K., P.H. Jacobsen, B. Hofmann, C. Meyer, H.J. Kolmos, P. Skinhoj, B. Norrild, and L. Mathiesen. 1997. Development of cytomegalovirus (CMV) disease may be predicted in HIV-infected patients by CMV polymerase chain reaction and the antigenemia test. AIDS (Lond.). 11:F21-F28.

25. Saltzman, R.L., M.R. Quirk and M.C. Jordan. 1992. High levels of circulating cytomegalovirus DNA reflect visceral organ disease in viremic immunosuppressed patients other than marrow recipients. J. Clin. Invest. 90:1832-1838.

26. Aspin, M.M., G.M. Gallez-Hawkins, T.D. Giugni, B. Tegtmeier, D.J. Lang, G.M. Schmidt, S.J. Forman, and J.A. Zaia. 1994. Comparison of plasma PCR and bronchoalveolar lavage fluid culture for detection of cytomegalovirus infection in adult bone marrow transplant recipients. J. Clin. Microbiol. 32: 2266-2269.

27. Brown, F., I. Arum, G. Francis, M. Patel, and S. Malcolm. 1997. Ganciclovir prodrug (RS-79070) - multiple dose, dose-ranging study with effect of food. Abstracts of the 4th Conference on Retroviruses and Opportunistic Infections. Session 88. Jan 22-26. Washington, D.C. IDSA Foundation for Retrovirology and Human Health. Alexandria, VA, p. 209. Abstract LB19.

28. Wang, L.H., R. Peck, P.Q. Chan, M. Youle, J. Eaves, and A. Bye. 1997. A phase I tolerability and pharmacokinetic (PK) trial of 1263W94, a novel antiHCMV agent, in HIV-infected volunteers. Abstracts of the 4th Conference on Retroviruses and Opportunistic Infections. Session 69. Jan 22-26. Washington, D.C. IDSA Foundation for Retrovirology and Human Health. Alexandria, VA, p. 189. Abstract 674 .

29. Lalezari, J., L. Drew, C. Jordan, P. Jensen, A. Moe, L. Reynolds, S. Mohanty, A. Cross, and L. Dunkle. 1997. In vivo anti-CMV activity and safety of oral lobucavir in HIV-infected patients. Abstracts of the 4th Conference on Retroviruses and Opportunistic Infections. Session 31. Jan 22-26. Washington, D.C. IDSA Foundation for Retrovirology and Human Health. Alexandria, VA, p. 220.301. 